\title{
Excellence In Business Education (A "FRUCE" Model For Higher Education Commission-Recognized Business Schools In Pakistan)
}

Nadir Ali Kolachi, Skyline University, UAE

Jan Mohammad, University of Baluchistan, Pakistan

\begin{abstract}
The paper develops a new model of the essential factors required to be a top business school in the world for the benefit of schools recognized by the Higher Education Commission (HEC) in Pakistan. Globally, top business schools are those that excel in research, attract strong faculty, and successfully foster student development. The present research considers these factors in relation to HEC recognition; HEC's stringent criteria are disliked by many educational entrepreneurs, for whom the profit motive can sometimes trump the delivery of high-quality programs, resulting in the awarding of spurious degrees.

HEC's criteria are intended to prevent situations like this, which became increasingly common in Pakistan and reduced educational quality. Under HEC recognition, top business schools and programs can once again be recognized. However, many business schools in Pakistan still have unqualified faculty, poor student development, and little or no research output. The present study shows that business schools in Pakistan can only survive if they explicitly or implicitly follow criteria based on the Faculty, Research, Use of Technology, Corporate Office, and Extracurricular Activities (FRUCE) model presented herein. The main motivation for presenting the FRUCE model is to help Pakistani business schools meet international standards.
\end{abstract}

As context, this research also reports on the slow progress of some universities in achieving adequacy in the areas included in the FRUCE model, including not only the areas mentioned above but also administration/governance and advising. The FRUCE model has the ability to address all these areas.

Keywords: FRUCE Model; HEC-recognized Business Schools

\section{INTRODUCTION}

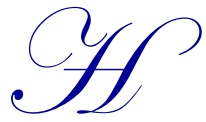

EC has given us a valuable understanding of the relative strengths and weaknesses of Pakistani business schools and set an excellent precedent in the presentation of benchmarks for these institutions. In particular, the issue of faculty lacking adequate credentials has come into focus as a result of HEC's efforts. The major efforts made under the former HEC chairman have been matched by the current chairman, which is a particularly good sign in the Pakistani context, where laudable efforts at improving institutions or processes have been seen at times in many fields but have not always been sustained.

While good teachers can command high salaries, bad teachers cost universities more in the long run, as they do not deliver required content and/or make an adequate contribution. Good teachers will support steps taken to achieve higher HEC rankings, while poor teachers will not since they themselves do not meet the criteria. We, as academicians, must appreciate the quality efforts of the schools that have reached the top rankings; we should be 
happy to see the progress of IQRA and Sukkur business schools, for example, which have built names for themselves in recent years and are now getting better results than many more established schools.

Faculty learning will be one effective ways for business schools to improve the organizational learning environment. If faculty are well trained, they can transfer their skills to students. Organizational learning is the process of improving organizational behaviors by acquiring and developing new knowledge and capabilities (Fiol \& Lyles, 1985). Knowledge is also continuous (March \& Olsen, 1976). Faculty must not be given a large teaching course load, which may make them lose interest in their work. Heavy teaching load, community-based research, and other responsibilities do result in stress (Fuhrmann, 1994; Goodwill, 1970; Spaights, 1980), which needs to be checked by HEC authorities.

Some universities view their faculty like teaching machines and keep them separated, which is not a good sign. Department heads should meet faculty on a regular basis to maintain open communication and foster an atmosphere of cordiality and respect. Open communication has long been considered as important element in faculty culture (Austin, 1990; Millet, 1962). It facilitates the creation of a congenial, sympathetic company of scholars in which friendships, productive conversation, and mutual aid can flourish (Bowen \& Schuster, 1986, p. 55). Conversely, where communication is constrained, faculty may feel isolated from colleagues and alienated from their work (Linholm, 2003; Tierney Bensimon, 1996). Similarly, university linkages to industry must be considered in terms of the social good, not simply the bottom line, as is currently the case for many low-ranked universities. Universities are the center of education, research, and knowledge creation and are crucial actors in innovation and in the promotion of economic development, which needs to be done in synergy with other institutions and industries (Etzkowitz 2004).

These distinctive features of the university raise the problem of identifying the proper frameworks for analyzing performance, particularly in terms of the intangible assets generated, such as knowledge. In the 1990s and 2000s, many concepts of intellectual capital were proposed (Bontis, 2002; Bontis, 2001; Bontis, 1998; Edvisson \& Malon, 1997; Kaplan \& Norton, 2004; Klien \& Prusak, 1994; Seemann et al., 2000). It is counterproductive when some inexperienced scholars criticize HEC and its work without seeing the initiative taken and the improvements made and without giving adequate credit to the very good work done by top business schools in accordance with HEC criteria. It is unfortunate that of the hundreds of business schools in Pakistan, barely one percent are achieving these benchmarks. Pakistani educators should be proud of institutions, like the Lahore University of Management Sciences (LUMS), for their achievements; other schools need to follow in their footsteps.

There is a very common saying in the sports world that if you learn from your experience, you are wise, but if you learn from others' experience, you are a genius. Why do Pakistani business and management professors - or in some cases, entire institutions - not produce high-quality papers or books, even when teaching for many years? What is wrong with this system? HEC's criticism of some people seems legitimate.

We must focus on these serious issues and strive to work on them. As mentioned earlier, bad teachers cost more than good teachers in the long run, since they do the same thing again and again but expect different results. Let us explore some new methods.

\section{WHAT MAKES A BUSINESS SCHOOL EXCELLENT? THE FRUCE MODEL FOR HEC- RECOGNIZED BUSINESS SCHOOLS}

This section presents the theoretical framework of this research paper, which is based on five essential parameters for the excellence of business schools. This theoretical framework is original and central to this research and the parameters have been generated on the basis of the essential operational needs of business schools. FRUCE stands for Faculty, Research, Use of Technology, Corporate Office, and Extracurricular Activities. The model is based on the authors' experience, expertise, and interest in contributing and guiding business schools in Pakistan and around the world with special reference to the successes of top HEC-recognized business schools. After frequent visits to top American, European, and Asian universities, we concluded that the FRUCE model can be very important to the success of any business school but that those that lack these five principles are substandard business schools focused on the bottom line. Table 1 explains the FRUCE Model based on relevant subheadings and the overall theme of the Model. 
Table 1: FRUCE Model

\section{FACULTY \\ - Qualifications (relevant doctoral degree(s)) \\ - Background and knowledge \\ - International experience \\ - Language skills \\ - Current knowledge \\ - Good grip on relevant literature}

- Experience (at least ten years' experience with at least $80 \%$ positive student evaluations)

- Pedagogy and teaching skills (respectful attitude, sense of humor, communication skills, ability to maintain control of the classroom, attentiveness, ability to remember names, counseling skills, interest in addressing students' concerns, motivational ability)

2. RESEARCH

○ High-quality research (based on impact factors and ISI-indexed publications)

- Development of good case studies and materials

- Number of books published

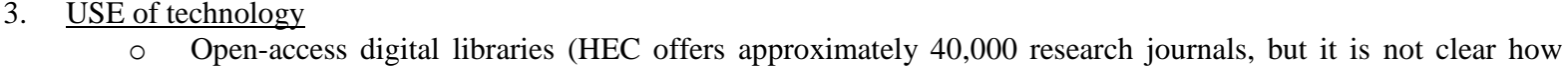
many faculty are using them and making their students aware of them)

- Faculty portal (for uploading lectures, attendance, and information on one's research; requesting information; and fostering student awareness of these tools to create a good technological culture in business schools)

4. CORPORATE office

○ Industry linkages (especially in curriculum development and consultancy work projects)

- Corporate training (the corporate office is the backbone of any university, and must be utilized by faculty for best service delivery)

- Professional development (for students and faculty)

○ Corporate dinners and visits (This will enhance students' exposure to and knowledge of the corporate world)

\section{EXTRACURRICULAR activities}

○ Sports facilities and special events (giving students a chance to relax and recharge)

In the following section, we will have a closer look at each point and present a detailed justification of the importance of the FRUCE model.

\subsection{Faculty}

Faculty are the most important part of any business school because they have the real power to motivate students and help them grow into business professionals and entrepreneurs. Most schools entice students to attend by touting their highly qualified faculty when, in fact, faculty are of low quality and student/teacher ratios are poor. Some Pakistani business schools failed to make the HEC list only because of faculty shortcomings. Parameters required for Faculty are listed in Table 2.

Table 2: Faculty

- Qualifications

- $\quad$ Background and knowledge

- Experience

- Pedagogy and teaching skills

\subsubsection{Qualifications}

A Ph.D. qualification is necessary for faculty at any good business school, but relevance is equally important. A Ph.D. in mechatronics does not qualify one to teach in a business school (just as a Ph.D. in management does not qualify one to teach mechatronics). This paper suggests that the bulk of teachers at a business school must have doctoral degrees in business fields. HEC should set criteria to address this concern; currently, there are many cases of inappropriate qualifications, even in HEC-recognized business schools. The names of these schools cannot be divulged, but university administrators and HEC officials know them. However, due to the shortage of Ph.D.s, we close our eyes to such issues at present. 


\subsubsection{Background And Knowledge}

Teaching management sciences is a complex endeavor and yet, many teachers have inadequate background and knowledge. These people cannot bring adequate real-life knowledge to their teaching practice. It is a must that faculty have visited a few other countries. We should begin to evaluate their training, consulting background, and related factors. This will help ensure that faculty are hired who can deliver their rich global competence to students.

\subsubsection{Experience}

Relevant experience is always important for business teachers. Breadth of experience is also important; if a person has taught the same material by rote for fifteen years, his or her experience may be much less rich than that of a colleague with many interesting experiences over that time. Evaluation of experience should also consider both business and academic experience. How many cases has the teacher read from HBR and how able is he or she to convey a wide range of ideas to students as a result?

\subsubsection{Pedagogy And Teaching Skills}

This category includes faculty background, knowledge, experience, patience, and interest in their teaching domain. Training can increase faculty competence in this regard. Some good universities have faculty visit each other's classes to observe the approaches their colleagues are using. Teaching is a complex art, contrary to some attitudes that see it as easy. To contribute, the teacher needs to explore how to be effective in the classroom setting. Some teachers finish their lectures before time and leave their students hanging because they did not plan well. Others always keep contingency cases and materials, like videos, on hand to fill extra time. During the survey and visits we conducted for this study, we became quite concerned about the teaching techniques that are being pursued at some business schools.

\section{$2.2 \quad$ Research}

There is an element of inspiration to good research and it takes time to instill research ability in teachers. Those who claim to take teaching as their profession must also be good researchers because teaching and research support each other and both make effective contributions. This point is often unappreciated and teachers doing research work may find it neglected by their peers.

It should be noted, however, that the situation here varies between state universities and business schools. The former are often much larger institutions with dozens of departments, while business schools may have less capacity to engage in research due to the teaching responsibilities of faculty. One way of addressing this will be to improve teaching course loads and student/teacher ratios, but larger social problems, labor action, and so on may still interfere. People in upper administrative positions in universities, who do not produce much in the way of research output, often do not appreciate the difficult situation of these teachers. Table 3 lists the points that are essential for Research.

Table 3: Research

- Development of good case studies and materials

- Number of books published

- Project opportunities and emergence of strong real-life businesses

\subsubsection{High-quality Research}

Business schools need help from HEC to provide training to faculty regarding the concepts of impact factors and ISI-indexed publications. As a scholar, the best way to improve one's research practice is to read thousands of ISI-indexed research papers available on the digital library provided by HEC for faculty research improvement. Especially for younger scholars, co-authored papers with senior colleagues will help them learn and provide expertise that they can rely on to cover their weak points. In time, following these practices will lead to a strong research culture. 


\subsubsection{Development Of Good Case Studies And Materials}

This area is particularly important for business schools. Business schools without case production and evaluation are like ships without rudders because they cannot transfer the basics of corporate expertise to students. Companies always look for new employees who can solve their problems. Without a strong case culture in business schools, how can students develop this ability? This is why students from good institutions in Asia that are highly known about cases get the jobs easily as LUMS and IIM Ahmadabad are the best examples in this situation. There must be a good case writing culture at all business schools. It often surprises us that HEC-recognized institutions, that have been providing business education for many years, have not produced strong written cases. HEC should conduct regular faculty training programs on case-building techniques and on using case studies to teach management sciences. This will also provide opportunities for students to fill research assistant positions.

\subsubsection{Number Of Books Published}

Publication record is another serious issue in HEC-recognized universities - perhaps one percent of book publications at top business schools, which is really not enough. We ourselves have never managed to produce a book. Book publication requires time and dedication beyond what is exhibited by business schools focused on the bottom line - a situation that turns faculty into mere class supervisors and research deadwood. Of course, the production of strong book-length studies requires familiarity with the research context, as well as strong writing skills, which are other areas that may be lacking.

2.2.4 Emergence of strong real-life businesses are the biggest areas of wastage in top business schools in the project assignments that place students in hundreds of companies every semester. Universities need to provide relevant practical work for their students, which is a continuous process relying on consultation with public- and private-sector partners.

With regard to the products of these projects, there is a common feeling that since they are often not of high quality (since the students are still learning), they are not useful and should be destroyed or let lapse. This is a major waste of energy and endeavor. In contrast, if students are supported, guided, and mentored by industry professionals, they can do work that is up to standard and useful to the organization in which they are placed. This is an area in which Pakistani schools can learn from those in the US, where projects initiated in business school often turn into successful businesses. Especially at top HEC-recognized business schools, there is a responsibility to support students better in this area. We suggest that the FRUCE model can be helpful in quality control.

\subsection{Use of technology}

Technology facilitates learning and makes our lives better. The advent of technology in the classroom is changing learning, and business schools in Pakistan must not be left behind. To evaluate the current situation in this regard, we evaluated technology usage at several universities, without explaining that that was our purpose (to ensure that we could get an accurate picture). We found that the top three business schools were very satisfactory in this regard, while the other two we visited were just satisfactory. Table 4 lists the importance of Use of Technology in teaching.

Table 4: Use of Technology

- Digital library

- $\quad$ Faculty portal

\subsubsection{Digital Library}

The digital library facility provided by HEC is a blessing for faculty and students, but unfortunately it is not utilized adequately, especially by institutions that offer master's degrees only (not doctoral degrees). The apparent lack of interest in this regard can be counteracted by a greater push from universities to help faculty and students be aware of these resources. 


\subsubsection{Faculty Portal}

Faculty portals update faculty and students on events, learning outcomes, and other pedagogical and assessment materials, as well as various other resources. During our visits, it was found that the introduction of computerized methods can save much time in areas like taking attendance. Further, lectures can be uploaded for the benefit of students and other faculty members. It is sometimes said that it takes three hours' preparation time to deliver a good one-hour lecture. Good universities maintain faculty portals for resource-sharing, but mediocre universities let work be duplicated, reducing teachers' time and energy for other endeavors like research. Other areas where computerized solutions can be useful are in combating plagiarism (using Turnitin), maintaining student records online (which is done by the top three schools), and creating forums for class activity, which is more appropriate when done in house than via (e.g.) Yahoo groups or webmail.

\subsection{Corporate office}

There has been a longstanding question why graduates from some business schools lack corporate leadership skills. A frequent argument is that they will learn on the job, but there is a minimum level of competence that must be reached in school before they can be useful employees. Some top institutions do manage to groom students to be job ready, which pays dividends in their professional lives. We have often written of the need for business schools to see students not as customers to be milked for their tuition money, but as the school's product and the companies that hire them as our customers. Therefore, alongside HEC's assessment of faculty and research, more attention has to be given to meeting the needs of actual businesses.

Some business schools are concerned only with making money, as previously noted, and not with delivering high-quality programming. These schools can leave their graduates lost in the corporate jungles on their own. Sometimes these students are critical of the lack of opportunity in the country but do not recognize the role of their own lack of ability in limiting their prospects. LUMS and IBA Karachi have the advantage of being very old schools with good reputations and alumni networks, but other schools must build good corporate relations. Table 5 mentions four important points for corporate office.

Table 5: Corporate Office

- Industry linkages

- $\quad$ Corporate training

- Professional development (for students and faculty)

- Corporate dinners and visits

\subsubsection{Industry Linkages}

Mediocre universities will see this as merely a buzzword, but good institutions take it very seriously and go to great lengths to maintain good relations with industry. Most business schools make great claims about their linkages with industry in their advertising materials, but research has shown this to be untrue in many cases. Many university heads have only a vague understanding of the concept of industry linkage as something like "getting students jobs." A broader conception of industry linkage includes corporate contributions to curriculum, board of studies, and collaboration to provide students with the skills demanded by industry, which, of course, will lead them to jobs as well. Maintaining a network of alumni, especially those at high levels in business, is essential in this regard.

\subsubsection{Corporate Training}

LUMS has an excellent executive center and IBA has a very strong corporate pool for training; other schools seem to be becoming much more active in this domain these days. HEC must appropriately value this activity, which will enhance academic-corporate relationships. 


\subsubsection{Professional Development (For Students And Faculty)}

In building the careers of their students, business schools have the opportunity to make a real contribution to society, and working with professionals will be important in this regard. Schools that are highly ranked must invite outsiders, such as trainers, managers, and bankers, to provide a new perspective and challenging and interesting lessons. This relates to the general issue of faculty development; IBA, Karachi is one school that has invested a huge amount of money recently to train its faculty to international standards. LUMS has also made great efforts in this area. In doing assessments, HEC must check university budgets for faculty and student development. Internationally, IESE (the Instituto de Estudios Superiores de la Empresa or "Institute of Higher Business Studies") at the University of Navarra in Spain has a very strong IFDP (International Faculty Development Program), and we found similarly well-designed programs at many American and Indian universities. Their purpose is to make faculty ready to do their job and equip them with the required skills and confidence to transform their students. Pakistani universities must take note of such initiatives and send their faculty abroad or invite outside experts in to help them improve professional development practices. It is very unfortunate that some mediocre business schools see faculty simply as teaching machines - an atmosphere that will demoralize even a good teacher in the long run. HEC should push institutions to focus on providing faculty with rewarding professional development options.

\subsubsection{Corporate Dinners And Visits}

These are a great opportunity for alumni, faculty, students, and corporate leaders to interact, learn, innovate, and cooperate. Business schools must invite industry experts to meet their students, who will learn confidence in communicating with senior people. This is one secret of the world's top universities, including top HEC-ranked institutions, to help them secure the future of their students. It is also an opportunity for industry people to come to know more about the schools and their plans, systems, students, and so on. This will open more avenues for business schools and their students.

Similarly, industry visits are an opportunity to familiarize students with the workings of corporations, including production, work methods, dealing with customers, IT, and the like. Students can thus relate the practical workings of real companies to what they learn at school. It is unfortunate that some HEC-recognized institutions give their students the excuse that they do not have the funding to arrange such trips or do not provide space for them in the students' schedule. This needs to be addressed.

\subsection{Extracurricular Activities}

It is important for students not to focus only on study and to get adequate exercise. LUMS and Sukkur IBA have good sporting facilities, while other schools have very limited space or none at all. Other events, like freshers' nights, fashion shows, tug of war, debates, film screenings, and so on, make the school a community. Table 6 lists important points essential for extracurricular activities.

Table 6: Extracurricular Activities

- $\quad$ Sport facilities

- $\quad$ Special events

\section{APPLICATION OF FRUCE MODEL TO HEC-RECOGNIZED BUSINESS SCHOOLS}

For this case-based research, a scale was developed to check the situation of HEC-recognized top business schools. Five schools met the criteria. The scale is $1=$ bad, $2=$ fair, $3=$ good, $4=$ very good, and $5=$ excellent. This scale has been previously used by HEC, but it has not previously been applied to FRUCE criteria. Table 7 explains the importance of FRUCE Model through application on five top business schools in Pakistan. All FRUCE parameters are evaluated and mentioned with each business school in order to check the ranking 
Table 7: Application of FRUCE Model

\begin{tabular}{|c|c|c|c|c|c|}
\hline & LUMS & IBA Karachi & IQRA & Sukkur IBA & NCBAE \\
\hline \begin{tabular}{ll}
\multicolumn{2}{l}{ Faculty } \\
- & Qualification \\
- & Background and knowledge \\
- & Experience \\
- & Pedagogy and teaching skills
\end{tabular} & $\begin{array}{l}5 \\
5 \\
5 \\
5\end{array}$ & $\begin{array}{l}4 \\
4 \\
5 \\
5\end{array}$ & $\begin{array}{l}5 \\
3 \\
4 \\
3\end{array}$ & $\begin{array}{l}3 \\
2 \\
4 \\
3\end{array}$ & $\begin{array}{l}3 \\
2 \\
4 \\
3\end{array}$ \\
\hline Total (Faculty) & 20 & 18 & 15 & 12 & 12 \\
\hline 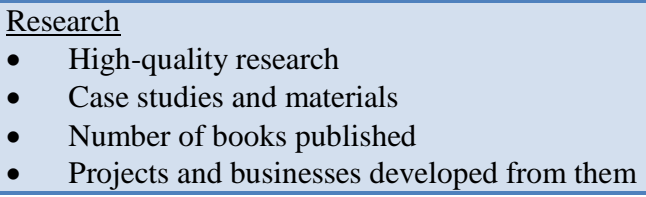 & $\begin{array}{l}5 \\
5 \\
4 \\
5\end{array}$ & $\begin{array}{l}3 \\
3 \\
3 \\
4\end{array}$ & $\begin{array}{l}4 \\
2 \\
2 \\
3\end{array}$ & $\begin{array}{l}3 \\
2 \\
2 \\
2\end{array}$ & $\begin{array}{l}3 \\
2 \\
2 \\
2\end{array}$ \\
\hline Total (Research) & 19 & 13 & 11 & 09 & 09 \\
\hline \begin{tabular}{ll}
\multicolumn{2}{l}{ Use of Technology } \\
- & Digital library \\
- & Faculty portal
\end{tabular} & $\begin{array}{l}5 \\
5\end{array}$ & $\begin{array}{l}5 \\
5\end{array}$ & $\begin{array}{l}4 \\
4\end{array}$ & $\begin{array}{l}3 \\
3\end{array}$ & $\begin{array}{l}3 \\
3\end{array}$ \\
\hline Total (Use of Technology) & 10 & 10 & 8 & 6 & 6 \\
\hline \begin{tabular}{ll}
\multicolumn{2}{l}{ Corporate Office } \\
- & Industry linkages \\
- & Corporate training \\
- & Professional development \\
- & Corporate dinners, visits
\end{tabular} & $\begin{array}{l}5 \\
5 \\
5 \\
5\end{array}$ & $\begin{array}{l}4 \\
4 \\
5 \\
5\end{array}$ & $\begin{array}{l}5 \\
3 \\
4 \\
3\end{array}$ & $\begin{array}{l}3 \\
2 \\
4 \\
3\end{array}$ & $\begin{array}{l}3 \\
2 \\
4 \\
3\end{array}$ \\
\hline Total (Corporate Office) & 20 & 18 & 15 & 12 & 12 \\
\hline Extracurricular Activities & 4 & 3 & 3 & 2 & 2 \\
\hline Total (Extracurricular Activities) & 4 & 3 & 3 & 2 & 2 \\
\hline Grand total & 73 & 62 & 52 & 41 & 41 \\
\hline
\end{tabular}

This model can guide business schools and identify the gaps among the performance of different schools, and it is congruent with HEC criteria as can be seen. LUMS is number one overall, IBA second, IQRA third, and Sukkur IBA and NCBA\&E maintain fourth position, respectively. The next-highest schools - SZABIST and IoBM can also learn from the FRUCE model and use it to improve their rankings.

\section{RESEARCH METHODOLOGY}

This paper adopts a qualitative methodology using structured and unstructured questionnaires, the authors' own knowledge, interviews, and the findings of previous literature to compare the FRUCE ratings of the five schools considered.

\subsection{Objectives Of The Study}

The objectives of this study were to evaluate HEC-recognized business schools and their real worth in business education, and to develop a model to improve business education in Pakistan. The FRUCE model's parameters show the features that are important for good, as opposed to mediocre, business education. The study was also intended to evaluate the FRUCE method in detail.

\section{CONCLUSION}

Failure to follow the principles reflected in the FRUCE model is one reason that many schools are not highly ranked by HEC. LUMS is the only institution that scores high in most FRUCE areas; IBA Karachi, the second-best, scores only at a satisfactory level. IBA is a good institution but does not take adequate account of HEC ratings for research output, publications, approved supervisor list, and teacher training. The other top schools show even more room for improvement. The cases of IQRA and Sukkur IBA can be a model for business schools that are strong but not in the top five. IQRA and Sukkur IBA are facing the challenge of maintaining their position. The FRUCE model, which reflects the best practices of institutions worldwide, will provide important guidance for these schools. 
This research has shown that SZABIST and IoBM have initiated so many programs to attract new students that the student/faculty ratio at these institutions is very high. This focus on attracting students and new programs, without a corresponding focus on facilities and faculty, is illogical. HEC's concern over this situation may be one reason why these institutions did not make the list, while IQRA, with its huge investment in faculty and research, did. The day can be foreseen when HEC will close down all business schools that do not meet its standards. There is still time for schools to address their issues by following the FRUCE model religiously. HEC is already educating parents about the worth of business schools, and this model will also be useful for those parents in helping them choose the best schools and fostering healthy business education in Pakistan.

\section{AUTHOR INFORMATION}

Dr. Nadir Ali Kolachi is an Associate Professor at Skyline University, University City of Sharjah, UAE. He has more than fifteen years of training, teaching, consultancy, and research experience at National \& International levels. Dr. Kolachi has earned an MBA, MS and Ph.D. in Management. He has delivered many keynote speeches \& research presentations on Management, HR, HRD, Change Management, OD, Management Education, Public Administration, Corporate Leadership and Organizational Communication in the USA, UK, Poland, Italy, Portugal, Pakistan, India and UAE. He is a Certified Corporate trainer of GAMMP International (Global Association of Management \& Marketing Professionals). E-mail: nadir.kolachi@gmail.com (Corresponding author)

Dr. Jan Mohammad is an Assistant Professor at University of Baluchistan, Quetta, Baluchistan, Pakistan. Dr. Jan Mohammad is a renowned professor in Management and Public Administration areas. He is also a member of various curriculum committees of higher education of the country. He has published many research papers on HR and Public Administration areas. Dr. Jan Mohammad is also a member of subject expert committee in the Public Sector University in Pakistan. He has also delivered many guest lectures on Public Administration in Pakistan.

\section{REFERENCES}

While much of this research is primary in nature, the following sources were also helpful.

1. Austin A (2002), Preparing the next generation of faculty, Journal of Higher Education 73(1), 94-122.

2. $\quad$ Bontis N (1998), Intellectual capital, Management Decisions 36, 63-76.

3. Bontis N (2001), Assessing knowledge assets, International Journal of Management Review 41-60.

4. $\quad$ Bowen H, Schuster (1986), American professors: A national resource imperiled, New York.

5. $\quad$ Edvisson, Malone (1997), New York: Harper Business.

6. $\quad$ Etzkowitz H (2004), International Journal of Technology \& Globalization 1(1), 64-77.

7. Fiol C, Lyles (1985), Organizational learning, Academy of Management Review, 10, 803-813.

8. Fuhrmann B (1994), Leadership issues for faculty, metropolitan universities, 71-77.

9. $\quad$ Kaplan, Norton (2004), Harvard Business Review, February, 52-63.

10. Klien, Prusak (1994), working paper, Center for Business Innovation, New York

11. Linholm J (2003), Perceived organizational fit, nurturing the minds, hearts and personal ambitions of university faculty, Review of Higher Education, 125-149.

12. Millet J (1962), The academic community, New York: McGraw Hill.

Websites

13. http://www.hec.gov.pk/INSIDEHEC/DIVISIONS/QALI/OTHERS/RANKINGOFUNIVERSITIES/Pages/

14. CategoryWise.aspx

14. $\quad$ www.iba.edu.pk

15. www.iba-suk.edu.pk

16. $\quad$ www.iqra.edu.pk

17. www.lums.edu.pk

18. $\quad$ www.ncbae.edu.pk 
NOTES 